\title{
IoT Based Smart Farming using Decision Support System
}

\author{
Mr. Muqueet ur Rehman, Dr. Sachin S. Agrawal, Dr. P. M. Jawandhiya
}

\begin{abstract}
Development in the agricultural process by adopting technology will be very useful in cultivation. Now in the agricultural sector, without understanding or monitoring the essential soil parameters, crop cultivation will be challenging and so the farmers may undergo financial losses. In agriculture, Expert systems are applied in a broad range of operations. Farmers usually depend on an agricultural specialist for decision making regarding crops, fertilizers, and farmland. This system can be used by the user having little knowledge of computer usage. It is a knowledge build decision support system for generating a decision on the basis of pre-existing knowledge. The development of IoT based devices for farming is changing the way of agriculture production by not only improving it but also making it cost-effective moreover time-efficient. Now a day's expert system and their decisions play an important role in every field. This study aims to design a decision support system for testing on various soil parameters. The results obtained by the system will be time-efficient and readily available to the farmers along within the limits set by the domain experts. This system can be used as decision support for monitoring soil by sensors. Multiple soil sensors are used to measure temperature, moisture, light, humidity, and $\mathrm{PH}$ value. The information from these soil sensors dipped into the soil sample is sent to the decision support system for the analysis. Finally, we can see the information saved to the server on the mobile phone as well as the laptop. Based on the information, we know which crop is suitable according to the particular soil parameter. Thus, this advanced technology with a decision support system helps the farmers to know the exact parameters of the soil making the soil testing method easier.
\end{abstract}

Index Terms - IoT, Server, Expert System, Sensors, Domain Experts.

\section{INTRODUCTION}

Soil is an uppermost layer of the earth's surface. Soil mainly consists of a mixture of minute particles of rocks, minerals, organic matter, and bacteria. Soil is formed by various natural activities such as temperature, rain, wind, as well as plants and animal that breaks the rocks into tiny pieces for a long period of time. Soil depth is not equal in all parts of the

Manuscript revised on August 19, 2020 and published on September 10, 2020

Mr. Muqueet ur Rehman, PLITMS, Buldana Maharashtra, India

Dr. Sachin S. Agrawal, COET, Akola Maharashtra, India

Dr. P. M. Jawandhiya, PLITMS, Buldana Maharashtra, India country. Somewhere it is only up to few centimeters deep or else at some places it may be measured up to 30 meters.

India has various types of soil and each soil has its own physical, chemical, and biological properties beneficial for different crop growth and its high yield.

- Red soil is rich in iron content and it is well suited for the crop like green gram, groundnut and castor seed.

- Black soil consists of high calcium, potassium, and magnesium nutrient but lacks nitrogen content that's compatible with the crop like cotton, tobacco, chilly, oilseeds, jowar, ragi, and maize.

- Though sandy soil has low nutrient content is suitable for growing trees such as coconut and cashew in high rainfall areas.

- Alluvial soil consists of heavy potassium content suitable for agriculture for crops such as paddy, sugarcane, and plantain.

For better crop production in the agriculture field, the soil needs to be monitored and test in proper time. The traditional method of soil testing requires more time, cost and effort. So, to overcome these drawbacks we need such a framework that provides an efficient on-time decision based on the specific soil parameters. Nowadays IoT based research is going on to overcome these difficulties. The Internet of Things (IoT) is a system where mechanical and digital machines are assigned with unique identifiers (UIDs) that are capable to transfer the data over the network without any human interaction.

The objective of this research paper is to develop an IoT based smart farming using a decision support system that provides decision regarding the suitable crop based on the various soil parameter such as soil moisture, humidity, temperature and $\mathrm{Ph}$ value.

\section{LITERATURE REVIEW}

The soil testing and their result play an important role in the selection of the crop for cultivation. But as the traditional soil testing method requires a laboratory test that may lead to extra effort and time for the proper result. Hence it is considered inefficient with respect to time. There is a pure need to overcome this problem with the new techniques of measuring the soil parameters by different sensors and enhance the system with the transparency of decision-based on them.

Most of the research is made in the context of soil parameters and suitable crops. The specific soil parameter is measured by the respective sensors as a PH sensor and on the single sensor, the system recommends a suitable crop. The $\mathrm{Ph}$ value provided by the $\mathrm{PH}$ sensor and the amount of Nitrogen, Phosphorus, and Potassium is evaluated on it. [1] Soil monitoring is the basic step involved in better crop production there must be a cost-effective solution. The system design uses a chemicals and color sensor kit to decode 
the soil nutrient value from the mixture. It mainly measures the PH value, concentration of other nutrients in the soil, and then transfers the data to the cloud. The system uses the Arduino mega 2560 connect with Wi-Fi ESP8266 to send data onto the cloud. [2] Mostly the soil moisture sensor along with the temperature sensor are implemented in the smart irrigation system. The irrigation system mainly includes raspberry pi, DHT11 sensor, and moisture sensor that gives the present values of the temperature, humidity, and moisture level of the soil. On the basis of these parameters, the pump is triggered ON/OFF either automatically or manually by the user to provide water without any efforts. If the moisture level goes down below the threshold value water pump gets on to maintain the soil moisture level. [3][4] Agriculture Stick based on IoT has been proposed to live to monitor the temperature and moisture by the Arduino kit, cloud computing, and solar technology. This stick aims to provide better yield with advanced caring of the crop with live data to the user. [5]

\section{Proposed Architecture}

The below figure shows the block diagram of the proposed IoT based smart farming using the decision support system.

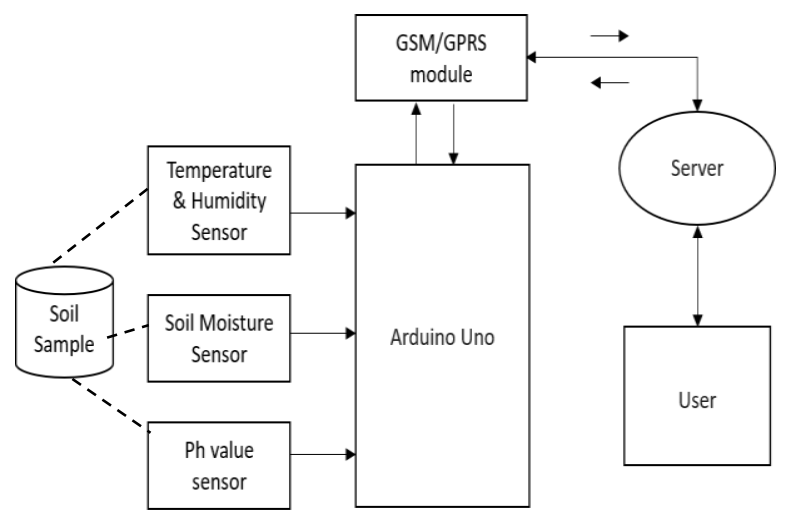

Figure 1: Block Diagram of the Proposed System

In this project, we have design a system that is important in the agricultural domain. This project consists of the following sensors temperature and humidity sensor, moisture sensor, ph value sensor. The soil moisture and ph value sensor are kept in the soil sample for measuring the moisture and ph value respectively. All the sensors are connected to the Arduino UNO Atmega328P kit via a breadboard. As the data from these sensors need to be transferred to the server for analysis we have implemented the GSM/GPRS module with the Arduino.

GPRS/GSM module enables the kit to communicate with the server. All the values are transferred to the server and precisely gets display on the web page. The web page can be provided with the suitable crop decision on the basis of the different soil parameter measured by their respective sensors.

\subsection{Components}

In this section, the various component including modules and sensors that are used in the project are discussed in detail.

\subsubsection{Arduino Uno}

Arduino Uno is nothing but the microcontroller-based with the ATmega328P. It consists of 14 input/output pins that support digital signal, six pins for analog inputs, $16 \mathrm{MHz}$ resonator, USB connection port, a power jack, an ICSP header along with the reset button. Arduino Uno includes everything that is required to support the microcontroller, it is easy to use just simply connect it to a computer with a USB cable or use AC to DC adapter for power or you can use the battery. The features from the programming languages $\mathrm{C}$ and $\mathrm{C}++$ are implemented by microcontrollers moreover, the Arduino also provides an integrated development environment (IDE) depend on the Processing language project.

"Uno" stands for one in the Italian language, which was selected to identify the release of Arduino Software (IDE)1.0.

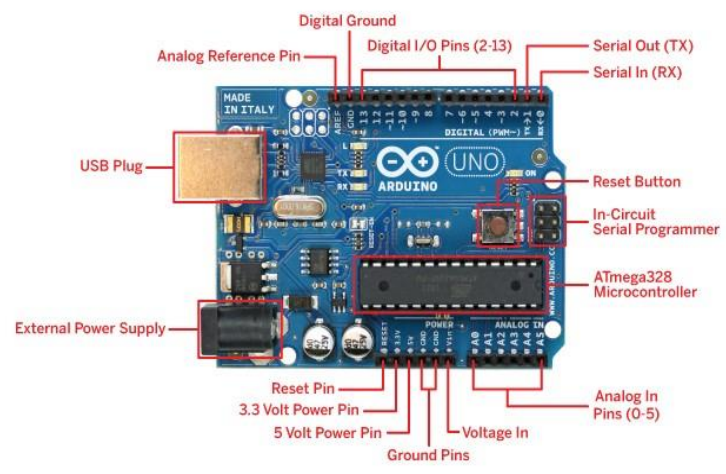

Figure 2: Arduino Uno ATmega328P kit

\subsubsection{GSM/GPRS Module}

The SIM900A is a wireless module known for its compactness and reliability. It is a small dimension full dual-band GSM/GPRS solution build in the SMT module to provides cost-effective solutions. The SIM900A module gives GSM/GPRS $900 / 1800 \mathrm{MHz}$ performance. It can supports calls, SMS, Data, and Fax in the little form factor along with the low power consumption. The GSM/GPRS Modem consists of an internal TCP/IP stack to enable you to connect with the internet through GPRS.

It has a power ON reset switch, a light indicator for showing the status of network and power, including sliding SIM holder. Stub antenna with the SMA connector and Power supply

$12 \mathrm{~V} / 2 \mathrm{~A}$.

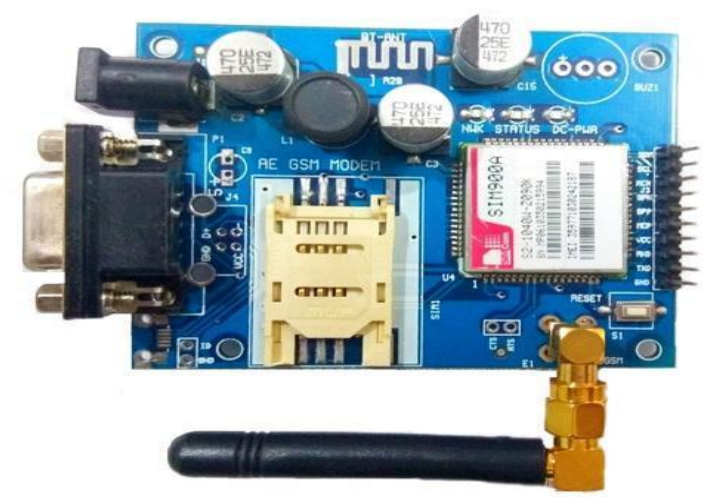

Figure 3: GSM/GPRS SIM900A Module 


\subsubsection{Soil Moisture Sensor}

The Soil Moisture Sensor FC-28 is used for measuring the moisture level in the soil and related materials. The soil moisture sensor is much simple and straight forward to use. It has four pins for VCC, GND, D0 for Digital output, and A0 for Analog output. Two probes of $5 \mathrm{~cm}$ in length each, that can be dipped into the soil sample under the testing. The circuit generates output in the form of voltage based on the conductivity of the soil. The soil between the two probes acts as a variable resistance whose value depends upon the moisture content in the soil sample. The resistance value across two probes ranges from infinity (for dry soil) to a very little resistance (for $100 \%$ moisture in the soil).

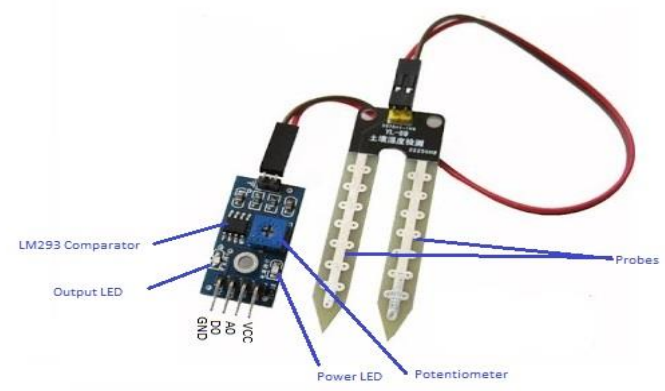

Figure 4: Soil Moisture Sensor FC-28

\subsubsection{Temperature \& Humidity Sensor}

The DHT11 sensor is commonly used to measure temperature and humidity. The sensor gives temperature and humidity value as output in the form of serial data. It has a dedicated NTC for the measurement of temperature and an 8-bit microcontroller. The DHT11 sensor is further factory calibrated, and therefore, it is easy to connect with other microcontrollers. This sensor can precisely measure temperature ranges from $0{ }^{\circ} \mathrm{C}$ to $50^{\circ} \mathrm{C}$ and humidity ranges from $20 \%$ to $90 \%$ with extreme precision of $\pm 1^{\circ} \mathrm{C}$ and $\pm 1 \%$. It has three pins VCC, Data pin and Ground indicated as +ve, out and -ve respectively.

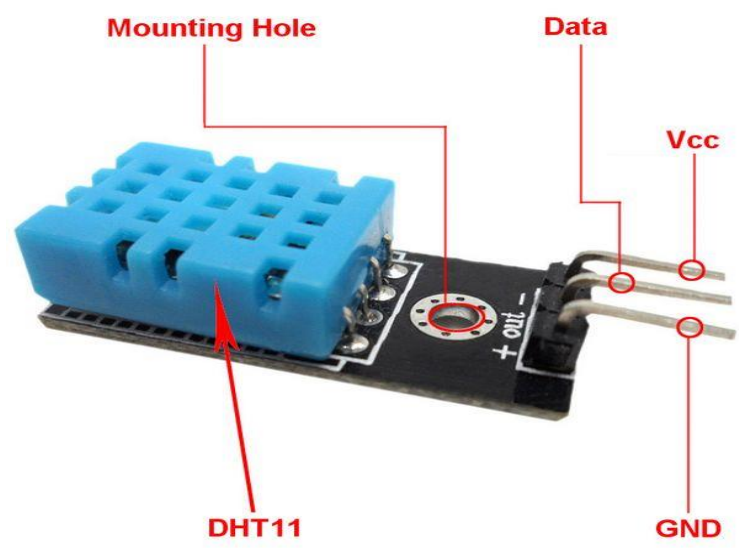

Figure 5: Temperature \& Humidity Sensor DHT11

\subsubsection{PH Sensor}

The PH sensor board is designed on the ATMEGA8 IC. It has additional onboard LDR for light value, a thermistor for the temperature value. The sensor gives the output in the form of serial data at its Tx pin. This can be used to obtain the $\mathrm{PH}$ value, the value of depth of rod immersed, light value, and temperature value. The $\mathrm{PH}$ sensors are generally used to measure the $\mathrm{pH}$ of liquids, but some special probes sometimes can be used to measure the $\mathrm{pH}$ of semi-solid materials. It has seven pins D7, D6, D5, 5V, GND, Tx, Rx from which only three pins are required to connect with Arduino that are 5v, GND and Tx.

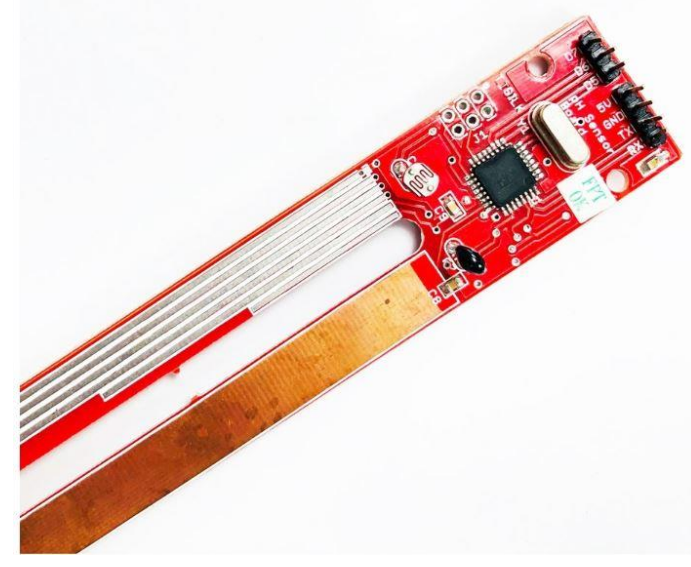

Figure 6: Ph Sensor

\subsection{Software used}

Arduino Software (IDE 1.8.13): The Arduino IDE is a platform-independent software tool, which is developed in Java, and also it is derived from the IDE for the Processing programming language and the wiring projects. A program or code written for any Arduino board is termed as "sketch". To compile the programs Arduino IDE uses the GNU toolchain and AVR Libraries. To upload the compiled code on the board it uses AVR-dude. The Arduino Software (IDE) is an open-source tool that makes it easy to code and upload it to the board. Due to cross-platform compatible with Windows, Mac OS X, and Linux operating systems. The environment for the software tool is written in Java and based on processing and another open-source software. This IDE can be used with any Arduino board effectively.

\section{SySTEM AlgorithM}

The proposed algorithm to describe the operation of the system.

\subsection{Algorithm}

Below is the algorithm of the proposed system.

Step 1 Start

Step 2 Deep soil sensors in the soil sample.

Step 3 Values are sent to the Arduino kit.

Step 4 GPRS module communicate with the server And sends the data of all sensors.

Step 5 All the data gets display on the webpage.

Step 6 Suitable crop is determined on the basis of the values of all sensors.

\subsection{Flow Chart}




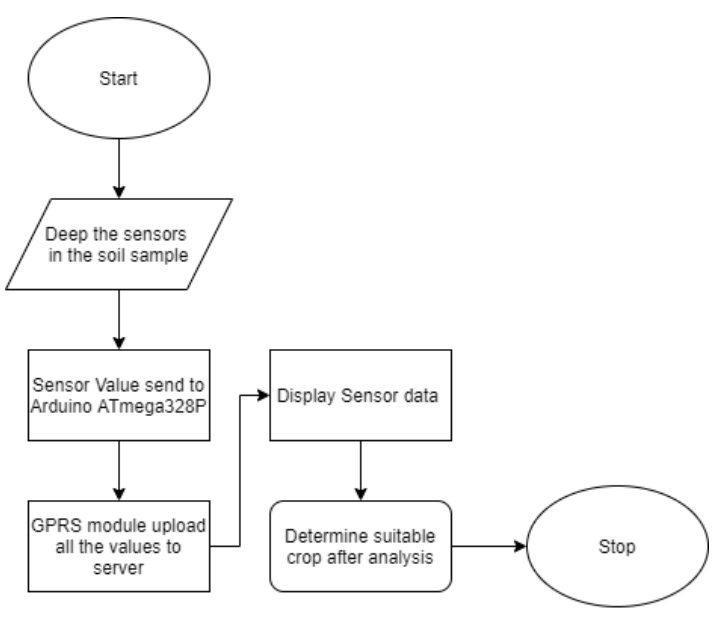

Figure 7: System Flow Chart

In this way, all the sensors connected to the Arduino are able to transfer the soil PH value, moisture value, temperature value, and humidity value to the webserver with the help of the GPRS module. The system should analyze the obtained value and provide a suitable crop recommendation as to the output of the soil sample. All the activities are controlled by the webpage that is capable of managing the soil parameters and provide the appropriate results.

\section{RESUlts}

A methodological strategy has been followed in designing the IoT based smart farming decision support system for measurement and analysis of the soil parameter. The results obtained from these soil parameters have shown that the execution of the system is quite easy and accurate. Soil test experiment has shown that soil moisture sensor, ph. sensor, temperature, and humidity sensor are very useful in the analysis of the respective soil parameters. This system can introduce to the new farming decision and can perform an important part in reducing the extra efforts and time as compared to traditional soil test methods.

\subsection{Connected Components and user interface}

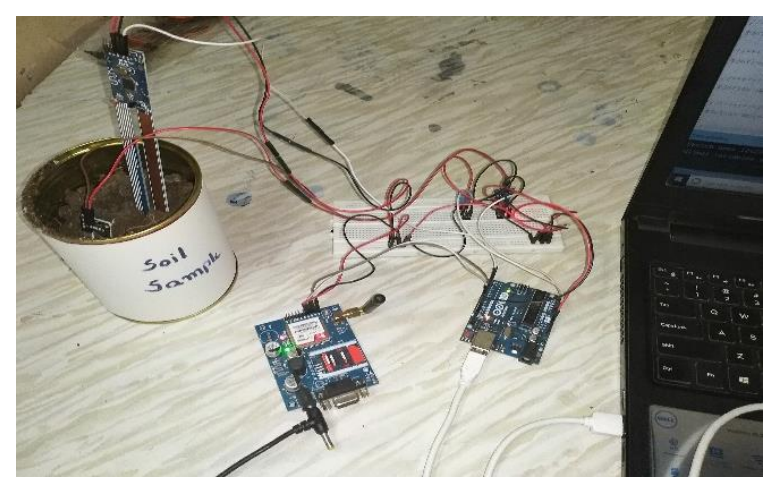

Figure 8: Sensors connected with Arduino Kit

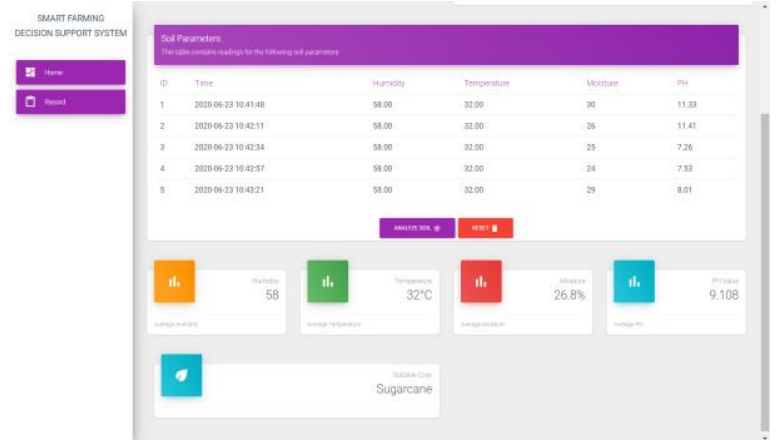

Figure 9: User Dashboard Screen

\section{Conclusion}

The IoT based Smart Farming using Decision Support system measures the soil $\mathrm{PH}$ value, moisture, temperature, humidity with the help of the PH sensor board, FC-28, DHT11 respectively. The sensors and Arduino kit of the proposed system interfaced successfully, and the wireless connection is established with the help of the GPRS module. The collected values of the soil parameters get stored on the remote server with the help of the SIM900A module and after the proper analysis based on an algorithm, the crop is defined.

\section{REFERENCES}

[1]Chaithra N T , Nagarathna ,NithiKumar "Measurable Nutrients and Available Sensors to Design a Soil Tester with Crop recommendation". IOSR Journal of Computer Engineering (IOSR-JCE) e-ISSN: 2278-0661, p-ISSN: 2278-8727, Volume 21, Issue 2, Ser. III (Mar - Apr 2019), PP 17-22.

[2]Arun Kumar, Abhishek Kumar, Akash De, Shashank Shekhar, Rohan Kumar Singh "IoT Based Farming Recommendation System Using Soil Nutrient and Environmental Condition Detection" International Journal of Innovative Technology and Exploring Engineering (IJITEE) ISSN: 2278-3075, Volume-8 Issue-11, September 2019.

[3]Mrs.T.Vineela, J. NagaHarini, Ch.Kiranmai, G.Harshitha, B.AdiLakshmi "IoT Based Agriculture Monitoring and Smart Irrigation System Using Raspberry Pi" International Research Journal of Engineering and Technology (IRJET) e-ISSN: 2395-0056 Volume: 05 Issue: 01 | Jan-2018 www.irjet.net p-ISSN: 2395-0072.

[4]Balakrishna.K, Nethravathi.S.N, Harshitha Krishna "Real-Time Soil Monitoring System for the Application of Agriculture" International Journal of Engineering Science and Computing (IJESC) ISSN 2321 3361 ㄷ 2016 IJESC Volume 6 Issue No. 5, May 2016.

[5] Anand Nayyar, Er. Vikram Puri "Smart Farming: IoT Based Smart Sensors Agriculture Stick for Live Temprature and Moisture Monitoring using Arduino, Cloud Computing \& Solar Technology" The International Conference on Communication and Computing Systems (ICCCS-2016).

[6] Dr. S. L. Satarkar, Dr. S. S. Agrawal, Prof. S. C. Makwana, Prof. P. V. Joshi "Decision Support System for Smart Agriculture using IoT" International Journal of Scientific Research and Review ISSN No.: 2279-543X Volume 07, Issue 04, April 2019.

[7] Sonali D. Gainwar, Dinesh V. Rojatkar "Soil Parameters Monitoring With Automatic Irrigation System" International Journal of Science, Engineering and Technology Research (IJSETR), Volume 4, Issue 11, November 2015. 
International Journal of Research in Advent Technology, Vol.8, No.8, August 2020

E-ISSN: 2321-9637

Available online at www.ijrat.org

\section{AUTHORS PROFILE}

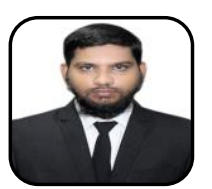

Mr. Muqueet ur Rehman, Student, Department of Computer Science \& Engineering, Pankaj Laddhad Institute of Technology and Management Studies Buldana, Maharashtra, India.

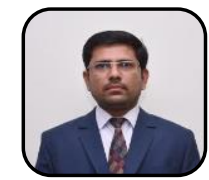

Dr. Sachin S. Agrawal, Associate Professor, Department of Computer Science \& Engineering, College of Engineering and Technology Akola, Maharashtra, India.

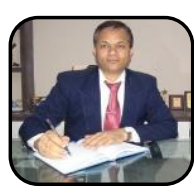

Dr. P. M. Jawandhiya Principal, Pankaj Laddhad Institute of Technology and Management Studies Buldana, Maharashtra, India. 